\title{
Detection of Kaposi's sarcoma-associated human herpes virus type 8 DNA in biopsy smears of human immunodeficiency virus-infected patients
}

\author{
Marcelo Corti ${ }^{1,2 *}$, María F Villafañe ${ }^{1,2}$, Humberto Metta ${ }^{1,2}$, Norberto Trione ${ }^{1,2}$, Patricia Baré ${ }^{3}$ and Leonardo Gilardi ${ }^{4}$ \\ ${ }^{1} \mathrm{HIV} / \mathrm{AIDS}$ Department, Infectious Diseases F. J. Muñiz Hospital, Buenos Aires, Argentina \\ ${ }^{2}$ Medicine Department, Infectious Diseases Orientation, University of Buenos Aires, School of Medicine, Buenos Aires, Argentina \\ ${ }^{3}$ Virology Laboratory, IIHEMA, IMEX-CONICET, National Academy of Medicine, Buenos Aires, Argentina \\ ${ }^{4}$ Ambulatory Medicine Subcoordinator, OSECAC, Buenos Aires, Argentina
}

\begin{abstract}
Introduction: Epidemic AIDS-associated Kaposi's sarcoma (KS) is the most aggressive form of this neoplasm and is strongly associated with the reactivation of human herpesvirus type 8 (HHV-8), particularly among men who have sex with men.

Objectives: To evaluate the presence of HHV-8 DNA in the biopsy smears of 31 patients with different clinical forms of AIDS-associated KS.

Materials and methods: Epidemiologic, clinic, immunologic and virologic characteristics of 31 HIV infected patients with KS were included in this descriptively and retrospectively analysis from 2010 to 2013. KS was classified in four clinical forms including only cutaneous lesions, only mucosal involvement, mucocutaneous compromise and disseminated disease. The detection of DNA HHV-8 was performed by polymerase chain reaction (PCR) in all biopsy smears by tissue disruption to perform the DNA extraction, DNA purification by spectrophotometry analysis and DNA amplification with specific oligonucleated primers.

Results: Thirty patients were male, the median of age was 34 years and the most frequent risk factor for HIV infection was unprotected sexual contact (90\%). The median of time between HIV infections to neoplasm diagnosis was 6 years. In 11 patients (35\%) KS was the first defining illness. The median of CD4 T cell count at the time of neoplasm diagnosis was 39 cell/ $\mu \mathrm{L}$. The majority of patients (84\%) were not receiving highly active antiretroviral therapy (HAART). Clinical forms includes 12 patients with cutaneous KS, 8 patients with mucosal KS, 7 patients with disseminated disease and 4 patients with mucocutaneous involvement. PCR HHV-8 was positive in $24(77 \%)$ biopsy smears. When we analyzed this group the median of age was 34 years, the median of time between HIV infection to neoplasm diagnosis was 9 years, the median the median of CD4 T cell count was $39 \mathrm{cell} / \mu \mathrm{L}$ and only 5 patients were receiving HAART at the time of diagnosis. No significant difference was observed between the HHV-8 positive and negative probable due to the small size of the cohort.
\end{abstract}

Conclusion: Although HHV-8 DNA was detected in a high number of patients in these series, it is possible that other mechanisms may be involved in the pathogenesis of AIDS-associated KS.

\section{Introduction}

Kaposi's sarcoma (KS) is a low-grade vascular tumor that may involve the skin, mucosa and viscera. KS was first reported in 1872 by Moritz Kaposi, a Hungarian dermatologist. This first description revealed that the neoplasm affects typically elderly patients of eastern or mediterranean Europeans and was described as "Idiopathisches Multiples Pigment Sarkom der Haut" [1,2]. Kaposi's described this tumor a longtime before the advent of the AIDS pandemic as a rare and relatively indolent disease involving the skin on the legs of elderly men [3]. After that, KS was classified in four clinical and epidemiological variants: 1) classic; 2) endemic or African; 3) iatrogenic or posttransplant and 4) epidemic or AIDS associated KS.

Epidemic AIDS associated KS is the most aggressive form of the disease and is strongly associated with the reactivation of human herpes virus type 8 (HHV-8) infection, particularly among men who have sex with men (MSM) [4]. The estimated prevalence of HHV-8 infection in different epidemiological studies demonstrated that half of all MSM are co-infected with HHV-8 and may develop KS within 5 to 10 years $[5,6]$.
The objective of this study was to evaluate the presence of HHV-8 DNA in the biopsy smears of 31 patients with different clinical forms of AIDS-associated KS.

\section{Materials and methods}

Epidemiological, clinical, immunological and virological characteristics of $31 \mathrm{HIV}$-infected patients with KS were included in this descriptive and retrospective analysis from 2010 to 2015 . KS was classified in 4 clinical forms: only cutaneous involvement, only mucosal involvement, mucocutaneous compromise and disseminated disease with lymph nodes and visceral involvement. In all patients diagnosis

Correspondence to: Marcelo Corti, Division “B”, Infectious Diseases F. J. Muñiz Hospital, Puán $38122^{\circ} \mathrm{C} 1406$ CQG, Buenos Aires, Argentina; E-mail: marcelocorti@fibertel.com.ar Key words: Kaposi's sarcoma, HHV-8, PCR, AIDS

Received: January 05, 2016; Accepted: January 20, 2016; Published: January 23 2015 
of KS was confirmed by the histopathological examination of biopsy smears obtained from cutaneous or mucosal lesions. The detection of DNA HHV-8 was performed including the following steps: 1) for tissue disruption, fresh and formalin fixed samples were used to perform the DNA extraction and detection of HHV-8. Briefly, disruption and homogenization of the fresh samples were carried out using a scalpel and a needle. For the formalin fixed samples, 10 fine slices of 10 microns were used. The samples were left overnight for complete lysis on a $56^{\circ} \mathrm{C}$ incubator with $200 \mathrm{ul}$ with the chaotropic salt-containing solution to insure the thorough denaturation of macromolecules. The genomic extraction was carried out with a commercial reagent, GenElute Mammalian genomic DNA miniprep kit from Sigma-Aldrich, following manufacturer recommendations; 2) for the DNA purification addition of ethanol causes DNA to bind when the lysate is spun through a silica membrane in a microcentrifuge tube. After several washes, DNA was eluted in $50 \mu \mathrm{l}$ of a Tris-EDTA solution. The concentration of purified DNA was determined by spectrophotometry analysis; 3 ) for the DNA amplification PCR was performed with specific primers for the viral capsid (KS3 tccgtgttgtctacgtcc, KS5 agccgaaggattccacc) with 5 to 10 $\mathrm{ul}$ of DNA in a total volume of $50 \mathrm{ul}$, with $1 \mathrm{ul}$ of each primer $(20$ $\mathrm{mM}), 10 \mathrm{mM}$ Tris/HCl (pH 8.3), $50 \mathrm{mM} \mathrm{KCl}, 1.5 \mathrm{mM} \mathrm{MgCl}$, each deoxynucleoside triphosphate at a concentration of $200 \mathrm{mM}$ and 1.25 $\mathrm{U}$ Taq DNA polymerase (Promega). After an initial denaturation step at $95^{\circ} \mathrm{C}$ for $5 \mathrm{~min}, 40 \mathrm{cycles}$ of PCR at $95^{\circ} \mathrm{C}$ for $30 \mathrm{~s}, 58^{\circ} \mathrm{C}$ for $30 \mathrm{~s}, 72^{\circ} \mathrm{C}$ for $30 \mathrm{~s}$ were carried out with a final extension at $72^{\circ} \mathrm{C}$ of $10 \mathrm{~min}$. A 233-nucleotide fragment of the viral capsid was amplified performing a PCR with specific oligonucleotide primers [7]. The PCR products were analyzed on a $2 \%$ agarose gel stained with ethidium bromide. All PCR runs included positive and negative controls.

\section{Results}

During the 5-year period, $31 \mathrm{HIV}$ infected patients were diagnosed with KS. Thirty patients were male, the median of age was 34 years and the most frequent risk factor for HIV infection was unprotected sexual contact $(90 \%)$. The median time between HIV-infection to neoplasm diagnosis was 6 years and the median of CD4 T-cell count at the time of neoplasm diagnosis was 39 cell $/ \mu \mathrm{L}$. KS was the first AIDSdefining illness in 11 (35\%) patients. The majority of patients (84\%) were not receiving highly active antiretroviral therapy (HAART). Epidemiological, clinical and immunological characteristics are listed in table 1. Clinical forms includes 12 patients with cutaneous KS, 8 patients with mucosal KS, 7 patients with disseminated disease and 4 patients with mucocutaneous involvement. PCR HHV-8 was positive in $24(77 \%)$ biopsy smears. When we analyzed only this group, the median of age was 34 years, the median of time between HIV-infection to neoplasm diagnosis was 9 years, the median of CD4 T-cell count was 39 cell/ $\mu \mathrm{L}$ and only 5 patients were receiving HAART at the time of diagnosis. No significant difference was observed between the HHV8 positive and negative results probable due to the small size of the cohort. Clinical forms of KS between patients with PCR HHV-8 (+) and PCR HHV-8 (-) in biopsy smears are detailed in table 2.

Table 1. Epidemiological, clinical and immunological characteristics of a series of $31 \mathrm{HIV}$ patients with KS in comparison only with PCR HHV-8 (+) in biopsy smears.

\begin{tabular}{|c|c|c|}
\hline & Total of patients n:31 & HHV-8 (+) n:24 \\
\hline Age (median) & 34 & 34 \\
\hline CD4 T cell count/ $\boldsymbol{\mu L}$ (median) & 39 & 39 \\
\hline With HAART in the onset of KS & $5(16 \%)$ & $5(20 \%)$ \\
\hline Median time since HIV infection & 6 years & 9 years \\
\hline Opportunistic diseases & $20(64.5 \%)$ & $15(62.5 \%)$ \\
\hline
\end{tabular}

Table 2. Clinical forms of KS between patients with PCR HHV-8 (+) and PCR HHV-8 (-) in biopsy smears.

\begin{tabular}{|c|c|c|}
\hline Clinical Forms of KS & PCR HHV-8 (+) n: 24 & PCR HHV-8 (-) n: 7 \\
\hline Cutaneous KS & $9(37.5 \%)$ & $3(43 \%)$ \\
\hline Mucosal KS & $7(29.1 \%)$ & $1(14 \%)$ \\
\hline Mucocutaneous KS & $4(16.7 \%)$ & 0 \\
\hline Disseminated KS & $4(16.7 \%)$ & $3(43 \%)$ \\
\hline Opportunistic diseases & $20(64.5 \%)$ & $15(62.5 \%)$ \\
\hline
\end{tabular}

\section{Discussion}

$\mathrm{KS}$ is an AIDS defining neoplasm that is strongly related with HHV-8 infection especially in patients with other sexually transmitted diseases and in the HIV seropositive subjects. Epidemiologic evidence indicated that AIDS-associated KS may have an infectious etiology. MSM AIDS patients are approximately 20 times more likely than hemophilic patients to develop KS and KS may be associated to specific sexual practice among MSM with AIDS [8]. The same herpes viruslike DNA sequences are present in AIDS-associated Kaposi's sarcoma, classic Kaposi's sarcoma, and the Kaposi's sarcoma that occurs in HIVnegative homosexual men [8]. Since the initial detection of HHV-8 in KS biopsy smears, some serological evidence implicates this viral agent with the development of the neoplasm. However, HHV-8 infection is a necessary factor but not sufficient condition in the etiology of all clinical forms of KS and not only to the AIDS-related variety [9]. Histopathological characteristics of KS include a wide spectrum of lesions ranged from pre-KS lesions also known as an in situ form of $\mathrm{KS}$ to the anaplastic KS, also named pleomorphic KS. Initial KS lesions include abnormal capillary-like vessels in an inflammatory infiltrate and, in some cases, a lymphangiogenesis arising in a setting of chronic lymphedema. On the other hand the anaplastic KS is an infiltrative solid tumor characterized by a proliferation of spindle tumor cells without vascular spaces seen mainly in AIDS-associated KS. This aggressive variant represents a greater degree of cellular and nuclear atypia, with high mitotic index and occasional necrosis. In the echymotic KS, the intradermal proliferation is accompanied by an extensive red blood cell extravasation (purpura effect) [10].

The global seroprevalence of HHV-8 is low, in contrast to other herpesvirus. The prevalence varies from $5 \%$ or less in the United States to more than $85 \%$ among children of African countries. HHV-8 DNA has been detected in oral epithelial cells and is eliminated in saliva, in $\mathrm{B}$ lymphocytes and mononuclear cells in the semen. The virus also can be detected in a cell-free state in the blood during the early phase of the natural history of the disease $[11,12]$. The different prevalence rates can be influenced by the transmission patterns and it is possible that the most important HHV-8 transmission source occurs primary via domestic or non sexual contact that involves saliva [13].

HHV-8 has a high ability to infect a range of cells including typical KS spindle cells, endothelial cells of the vascular space of KS lesions, monocytes in KS lesions, B lymphocytes in the peripheral blood, primary effusion lymphomas and Multicastelman-related neoplasia and in keratinocytes of the skin [14]. Like other herpesvirus, HHV-8 remains latent within these cells and develops a variety of mechanisms to evade the host immune system.

Pauk et al. [15] in a cohort of 50 patients HIV seropositive, detected HHV -8 in $34 \%$ of oropharingeal samples, $5 \%$ of semen samples, $1 \%$ of anal samples and $0.3 \%$ of urethral samples. In the comparison with oral samples with genital and anal samples, the detection of HHV-8 
DNA in oral epithelial cells suggests that these cells can be a reservoir of the virus $(\mathrm{p}<0.001)$.

Not all the persons infected by HHV-8 develop KS [16]. Orozco et al. [17] studied 24 patients with KS; 22 of them were seropositive for HIV. In the group of patients with KS and HIV, $83.3 \%$ were seropositive for HHV-8. In other studies the presence of detectable antibodies against HHV-8 was from $11 \%$ to $54 \%$ in the HIV-seropositive patients [18-21].

In a large cohort of patients co-infected by HIV and HHV-8, Martin et al. detected that the presence of HHV-8 antibodies preceded and it was strongly associated with the subsequent development of KS. In the same study, the median time to develop KS in the co-infected subjects was approximately 10 years [22].

Chang et al. [7] analyzed 27 tissue samples of patients with KS by three different techniques. Southern Blot DNA hybridization in comparison with PCR. PCR was more sensitive (93\%) than Southern Blot hybridization (78\%) to detect DNA HHV-8. In our cohort PCR was positive in $77 \%$ of biopsy smears.

HHV-8 infection alone appears to be insufficient for the development of KS. The HHV-8 life cycle presents two different phases: a primary and generally asymptomatic infection followed by a latent period and a lytic period characterized by the viral replication.

It is possible that other mechanisms must be involved in the pathogenesis of HIV-associated KS. In this aspect HIV infection can be a cofactor for the development of KS but it is important to emphasize that HIV is not necessary for KS occurrence. Despite other cofactors may exist, none of them have the importance of HIV co-infection.

\section{References}

1. Boschoff C, Weiss RA (2001) Epidemiology and pathogenesis of Kaposi's sarcomaassociated herpesvirus. Philos Trans R Soc Lond B Biol Sci 356: 517-534. [Crossref]

2. Kaposi M (1872) Idiopathisches multiples pigment sarkom der Haut. Arch Derm Syph 4: $265-73$.

3. Haubrich WS (2003) Kaposi of Kaposi's sarcoma. Gastroenterology 125: 327.

4. Nawar E, Mbulaiteye SM, Gallant JE (2005) Risks factors for Kaposi's sarcoma among HHV-8 seropositive homosexual men with AIDS. Int J of Cancer 115: 296-300.

5. Viejo-Borbolla A, Schultz TF (2003) Kaposi's sarcoma-associated herpesvirus (KSHV/HHV8): key aspects of the epidemiology and pathogenesis. AIDS reviews 5: 222-229. [Crossref]

6. Hansen A, Boshoff C, Lagos D (2007) Kaposi sarcoma as a model of oncogenesis and cancer treatment. Exp Rev Antican Ther 7: 211-220. [Crossref]
7. Chang Y, Cesarman E, Pessin MS (1994) Identification of herpesvirus-like DNA sequences in AIDS-associated Kaposi's sarcoma. Science 266: 1865-1869. [Crossref]

8. Moore PS, Chang Y (1995) Detection of herpesvirus-like DNA sequences in Kaposi's sarcoma in patients with and those without HIV infection. $N$ Engl J Med 332: 11811185. [Crossref]

9. Simonart T (2006) Role of environmental factors in the pathogenesis of classic and African-endemic Kaposi's sarcoma. Cancer letters 244: 1-7.

10. Radu O, Pantanowitz L (2013) Kaposi Sarcoma. Arch Pathol Lab Med 137: 289-294. [Crossref]

11. Huang YQ, Li JJ, Poisez BJ (1997) Detection of herpesvirus-like DNA sequences in matched specimens of semen and blood from patients with AIDS-related Kaposi's sarcoma by polymerase chain reaction in situ hybridization. Am J Pathol 150: 147-153. [Crossref]

12. Harrington WJ, Bagastra O, Sosa CE (1996) Human herpesvirus type 8 DNA sequences in cell-free plasma and mononuclear cells of Kaposi's sarcoma patients. J Infect Dis 174: 1101-1105. [Crossref]

13. Dukers NH, Rezza G (2003) Human herpesvirus 8 epidemiology. What we do and what we don't know. AIDS 17: 1717-1730.

14. Sadagopan S, Sharma-Walia N, Veettil MV, Raghu H, Sivakumar R, et al. (2007) Kaposi's sarcoma-associated herpesvirus induces sustained NF-kappa B activation during de novo infection of primary human dermal microvascular endothelial cells that is essential for viral gene expression. J of Virol 81: 3949-3968. [Crossref]

15. Pauk J, Huang ML, Brodie SJ, Wald A, Koelle DM, et al. (2000) Mucosal shedding of human herpesvirus 8 in men. NEJM 343: 1369-1377. [Crossref]

16. Ganem D (2006) KSHV infection and the pathogenesis of Kaposi's sarcoma. Annual Review of Pathol 1: 273-296. [Crossref]

17. Orozco B, Gomez LM, Estrada S, Restrepo BN, Cataño JC (2007) Relationship between human herpes virus 8 and Kaposi sarcoma in HIV positive and negative patients. Infection 11: 111-116. [Crossref]

18. Blackbourn DJ, Osmond D, Levy JA, Lennette ET (1999) Increased human herpesvirus 8 seroprevalence in young homosexual men who have multiple sex contacts with different partners. J Infect Dis 179: 237-239. [Crossref]

19. O’Brien TR, Kedes D, Ganem D, Macrae DR, Rosenberg PS, et al. (1999) Evidence for concurrent epidemics of human herpesvirus 8 and human immunodeficiency virus type 1 in US homosexual men: rates, risk factors, and relationship to Kaposi's sarcoma. J Infect Dis 180: 1010-1017. [Crossref]

20. Kedes DH, Operskalski E, Busch M, Kohn R, Flood J, et al. (1996) The seroepidemiology of human herpesvirus 8 (Kaposi's sarcoma-associated herpesvirus): distribution of infection in KS risk groups and evidence for sexual transmission. Nat Med 2: 918-924. [Crossref]

21. Gao SJ, Kingsley L, Li M, Zheng W, Parravicini C, et al. (1996) KSHV antibodies among Americans, Italians, and Ugandans with and without Kaposi's sarcoma. Nat Med 2: 925-928. [Crossref]

22. Martin JN (2007) The epidemiology of KSHV and its association with malignan disease. Human Herpesviruses: Biology, Therapy, and Immunoprophylaxis. Cambridge: Cambridge University Press, UK.

Copyright: (C2015 Corti M. This is an open-access article distributed under the terms of the Creative Commons Attribution License, which permits unrestricted use, distribution, and reproduction in any medium, provided the original author and source are credited. 